\title{
O PAPEL DA ADMINISTRAÇÃO NA MANUTENÇÃO DAS ORGANIZAÇÕES
}

\author{
Kaio Caldeira dos Anjos, Matheus Henrique Vinha da Silva, Thais Rubia Ferreira Lepre \\ Universidade do Oeste Paulista - UNOESTE, Curso de Ciências Contábeis, Presidente Prudente, SP. E-mail: \\ thaisrubia@unoeste.br
}

\begin{abstract}
RESUMO
Vivemos um momento de transformações em todos os aspectos da sociedade mundial. E como reflexo destas mudanças, as organizações tem enfrentado grandes desafios na luta pela sobrevivência no mercado. E como a administração é o alicerce das empresas entende-se que ela esta relacionada com esta sobrevivência ou não das organizações, neste sentido este artigo objetiva identificar como a administração das organizações esta relacionada com os pedidos de falência das mesmas. E como forma de alcançá-lo o estudo foi realizado através de abordagem qualitativa e pesquisa bibliográfica. Justificando sua existência pela necessidade de mostrar aos gestores que a qualidade da gestão é determinante para que a falência não ocorra. Diante disso, conclui-se que a administração é responsável por direcionar os departamentos e portanto, a organização como um todo, sendo que as decisões tomadas em um setor refletem nos demais e consequentemente em todo conjunto, podendo contribuir para permanência ou falência do negócio no mercado.
\end{abstract}

Palavras-chave: Administração. Falência. Sobrevivência. Recuperação Judicial. Organizações.

\section{THE BOARD'S ROLE IN SERVICE ORGANIZATIONS}

\begin{abstract}
We live in a time of changes in all aspects of society worldwide. And as a result of these changes, organizations have faced major challenges in the struggle for survival in the market. And how management is the foundation of the companies it is understood that it is related to this survival or otherwise of the organizations in this sense this article aims to identify how management of this related to the bankruptcy filings of the same organizations. And in order to achieve it the study was conducted through qualitative approach and literature. Justifying their existence by the need to show managers that the quality of management is crucial for the failure does not occur. Therefore, it is concluded that the administration is responsible for directing the departments and therefore the organization as a whole, and that decisions taken in one sector reflect in others and consequently across whole and may contribute to residence or business bankruptcy Marketplace.

Keywords: Administration. Bankruptcy. Survival. Judicial Recovery. Organizations.
\end{abstract}




\section{INTRODUÇÃO}

A sociedade brasileira, assim como a mundial, experimenta há alguns anos um período drástico de mudanças em todas as esferas, em especial as organizações por serem a base de qualquer país (produzem, geram empregos e renda) têm enfrentado um mercado bastante competitivo e turbulento.

E isso se deve a junção de vários acontecimentos, com destaque para: abertura dos mercados, popularização da internet, desenvolvimento tecnológico acelerado, e políticas de incentivo a abertura de micro e pequenas empresas. E como forma de atender estas novas demandas as organizações nas ultimas décadas deixaram de preocupar-se apenas com a manutenção dos negócios no mercado, passando a pensar em formas de diferenciar-se para competir e sobreviver. E sendo a administração das organizações a responsável pelo direcionamento e pela tomada de decisão em todos os aspectos, tendo em vista que "administração nada mais é do que a condução racional das atividades de uma organização" (CHIAVENATO, 2004, p.02), pode-se dizer que ela tem papel definidor na sobrevivência do negócio no mercado.

Mas para compreender melhor este papel e o porque de tanta importância, é necessário pormenorizar a administração em todas as áreas e esferas que ela atua dentro das organizações. Segundo Lacombe (2009) a administração deve estar presente em todos os níveis hierárquicos: no nível de direção, no nível gerencial e no nível de execução. Ou seja, ela exerce papel essencial desde o alto escalão, onde se define a longo prazo o futuro da organização, até o operacional, onde se realiza as atividades voltadas para viabilização da atividade econômica que a empresa se destina.

E além disso, é comum as empresas departamentalizarem suas atividades por função, onde há uma administração voltada especificamente para cada área relevante ao funcionamento do negócio. Como salienta Oliveira (2002) dentre os tipos de departamentalização existentes, a funcional é bastante utilizada, tem a finalidade de agrupar atividades semelhantes para compor uma unidade organizacional. Assim, de acordo com as necessidades de cada negócio, cria-se departamentos diferentes. Pois,

não existe um modelo mais indicado para todos os casos. O segredo para uma organização bem-sucedida está justamente na ideia de adequação. Em outras palavras, o melhor tipo de estrutura organizacional será sempre aquele que atender da melhor maneira às necessidades específicas de cada empresa.(LLATAS, 2012, p. 30). 
Neste sentido, é possível perceber que não existe uma forma geral de realizar a divisão por departamentos, ela deve ser pensada observando as especificidades de cada empresa. Porém, existem alguns departamentos comuns a boa parte das organizações, entre eles está o departamento de financeiro, o departamento comercial e o departamento operacional, básicos ao funcionamento de qualquer empresa, e totalmente relacionados, como evidencia Llatas (2012, p. 30) "a dinâmica do funcionamento de uma empresa e a do corpo humano são parecidas em alguns pontos [...] Basta que um desses órgãos não funcione direito para que todo o conjunto adoeça".

Ou seja, a falha em qualquer departamento prejudica o negócio de modo geral. E tendo em vista que a boa parte dos erros acaba ocasionando prejuízos financeiros para as organizações seja direta ou indiretamente "esse processo decisorial básico ao sucesso de toda empresa vem assumindo complexidades e riscos cada vez maiores na economia brasileira" (ASSAF NETO; LIMA, 2014, p. 02). Ao passo que a má situação financeira pode acarretar insolvência, que é tida como sinônimo de falência. Temida por gestores e empresários, como evidencia Mamede (2014, p. 0102, grifo nosso):

A insolvência, a incapacidade de adimplir as obrigações, é normalmente objeto da ampla repreensão social. Palavras como insolvente, falido, quebrado estão marcadas por um valor negativo, vexatório, intimamente ligado à ideia de caloteiro, criminoso, fraudador, desonesto, trapincola, entre outros [...] Toda essa incompreensão e agressividade derivam da impressão geral de que o insolvente chegou a esse estado porque quis, por ser desonesto. [...]É claro que a insolvência pode resultar de atos dolosos, de desonestidade; o devedor pode, sim, ter desejado passar os credores para trás. Também pode resultar de culpa grave, fruto da desídia extrema para com os negócios, imprudência exagerada na sua condução, abusos no direito de administração, em desproveito da segurança alheia etc.

As ideias do autor reforçam a importância da administração, com destaque para financeira, na sobrevivência dos negócios no mercado e externa a ideia que a sociedade faz de empresários falidos. Mas afinal, o que é falência?

Para Oliveira (2005, p. 324), “[...] é um processo judicial de execução concursal de credores sob o patrimônio do devedor empresário que deixou de efetuar na data do vencimento o pagamento de suas obrigações líquidas". Ou seja, é um processo em que a empresa deixa de existir, devido a falta de condições financeira de arcar com os compromissos assumidos com os credores.

A falência é prevista nas leis brasileiras desde a década de 40, através do Decreto - Lei no 7.661, de 21 de junho de 1945. Segundo o artigo 10 deste decreto "considera-se falido o comerciante que, sem relevante razão de direito, não paga no vencimento obrigação líquida, 
constante de título que legitime a ação executiva". Assim, a falência era tida como única forma de solucionar o problema das empresas com insolvência financeira, porém, ao longo dos anos, percebeu-se que tentar recuperar estas organizações para, mantê-las ativas no mercado é mais vantajoso a economia do país, ao passo que esta mantém pessoas empregadas, e comercializando mercadorias e/ou serviços. Para Fonseca e Kohler (2005, p.03):

[...] a nova Lei enfatiza o surguimento de empresas viáveis que estejam passando por dificuldades temporárias, a fim de evitar que a situação de crise culmine com a falência. Nesse sentido, é extinta a ineficiente concordata e criado o instituto da recuperação judicial, que tem como principal característica o oferecimento aos credores de um plano de recuperação, que, na prática, envolverá negociações e concessões mútuas, além de providências e compromissos do devedor visando a persuadir os credores da viabilidade do plano.

Em outras palavras, a reformulação na lei pode beneficiar bastante os empresários, com a continuidade das suas atividades. De acordo com o Capitulo III, seção 1 da Lei no. 11.101 de 9 de fevereiro de 2005:

A recuperação judicial tem por objetivo viabilizar a superação da situação de crise econômico-financeira do devedor, a fim de permitir a manutenção da fonte produtora, do emprego dos trabalhadores e dos interesses dos credores, promovendo, assim, a preservação da empresa, sua função social e o estímulo à atividade econômica.

Portanto, esta nova lei pode ser considerada uma espécie de segunda chance para empresa que por má administração acabaram com insolvência financeira e perigando falir.

Com base em tudo que foi exposto até aqui, é possível reforçar a tese de que a sobrevivência das empresas depende em grandes proporções da forma que são administrados os seus departamentos, onde o resultado pode ser positivo ou negativo. "O processo de tomada de decisões reflete a essência do conceito de administração. Reconhecidamente, administrar é decidir, e a continuidade de qualquer negócio depende da qualidade das decisões tomadas por seus administradores nos vários níveis organizacionais" (ASSAF NETO; LIMA, 2014, p.02). Em outras palavras, a administração esta intimamente relacionada a falência, ao sucesso ou a recuperação judicial de qualquer negócio tendo em vista que a gestão adequada dos departamentos contribui efetivamente para saúde financeira da organização e sua manutenção no mercado

Em vista disso, o objeto desse artigo é identificar como a administração das organizações esta relacionada com os pedidos de falência das mesmas. 


\section{METODOLOGIA}

Este artigo foi elaborado com base em uma abordagem qualitativa, que de acordo com Gonsalves (2005, p. 58) "[...] preocupa-se com a compreensão, com a interpretação do fenômeno, considerando o significado que os outros dão às suas práticas". Neste sentido, a pretensão é abordar subjetivamente os fatos, de modo interpretativo sem mensuração ou emprego de análises estatísticas.

Como instrumento de coleta de informações, foi utilizada a pesquisa bibliográfica que para Marconi e Lakatos (2010, p. 142) “[...] é um apanhado geral sobre os principais trabalhos já realizados, revestidos de importância, por serem capazes de fornecer dados atuais e relevantes relacionados com o tema". Ou seja, esta pesquisa foi viabilizada por meio de livros, leis e materiais já divulgados oferecendo uma nova visão a partir da junção do que foi encontrado.

\section{RESULTADOS E DISCUSSÃO}

Segundo dados disponibilizados pelo Serasa Experian em março de 2015 o número de pedidos de falência subiu em 57,3\% e, em comparação a março de 2014 , esse número subiu em 6,1\%. Dentre os 140 pedidos, 69 foram requisitados por micro e pequenas empresas, 32 de médias e 39 de grandes. Fato que evidencia que independente do porte, as organizações têm passado por dificuldades financeiras, que tem acarretado insolvência.

E estas dificuldades podem advir do desarranjo em qualquer departamento, como reflexo de algum fator externo ou interno, porém, é função da administração solucionar ou minimizar os efeitos destas nos resultados organizacionais.

Neste sentido, os resultados encontrados com esta pesquisa mostram que a administração esta envolvida com todas as tomadas de decisão nas organizações e que apesar do cenário externo refletir na competitividade do negócio, é do administrador a função de escolher o caminho a seguir, portanto, a qualidade da gestão, impacta na saúde financeira, e pode levar qualquer negócio a falência.

\section{CONCLUSÃO}

Este artigo teve como motivação descobrir como a administração das organizações esta relacionada com os pedidos de falência das mesmas, e ao longo do estudo, com base nos dados coletados bibliograficamente foi possível concluir que a administração tem a função de direcionar os caminhos trilhados pelo negócio no mercado, e só é possível realizar este direcionamento 
porque ela esta presente em todos os níveis hierárquicos e em todos os departamentos, sendo que as decisões tomadas em um setor refletem nos demais e consequentemente em todo conjunto organizacional, podendo contribuir para permanência ou falência do negócio no mercado.

\section{REFERÊNCIAS}

ASSAF NETO, A.; LIMA, F. G. Fundamentos de Administração Financeira. 2.ed. São Paulo: Atlas, 2014

BRASIL. Decreto Lei n. 7.661, de 21 de junho de 1945. Lei de Falências. Disponível em: < http://www.planalto.gov.br/ccivil 03/decreto-lei/del7661.htm>. Acesso em: 25 mai. 2015.

BRASIL. Lei Federal n. 11.101, de 09 de fevereiro de 2005. Regula a Recuperação Judicial, a Extrajudicial e a Falência do Empresário e da Sociedade Empresaria. Senado Federal: 2005. Disponível em: < http://www.planalto.gov.br/ccivil 03/ ato 2004-2006/2005/lei/l11101.htm>. Acesso em: 25 mai. 2015.

CHIAVENATO, I. Introdução à teoria geral da administração. 7.ed. Rio de Janeiro: Editora Campus, 2004.

FONSECA, H. L. P.; KÖHLER, M. A. A nova Lei de Falências e o Instituto da Recuperação Extrajudicial. Brasília: Consultoria Legislativa do Senado Federal - COORDENAÇÃO DE ESTUDOS, 2005. Disponível em: < http://www12.senado.gov.br/publicacoes/estudos-legislativos/tipos-deestudos/tex tos-para-discussao/td-22-a-nova-lei-de-falencias-e-o-instituto-da-recuperacao-extraju dicial>. Acesso em: 25 mai. 2015.

GONSALVES, E. P. Conversas sobre iniciação à pesquisa científica. 4. ed. Campinas: Alínea, 2005.

LACOMBE, F. Teoria geral da administração. São Paulo: Saraiva, 2009.

LLATAS, M. V. Organização Sistemas e Métodos. 1.ed. São Paulo: Pearson Prentice Hall, 2012.

MAMEDE, G. Direito Empresarial Brasileiro: Falência e Recuperação de Empresas. 6.ed. São Paulo: Atlas, 2014

MARCONI, M. A.; LAKATOS, E. M. Fundamentos de metodologia científica. 7. ed. São Paulo: Atlas, 2010.

OLIVEIRA, C. M. Comentários à nova lei de falências. São Paulo: Thomson, 2005.

OLIVEIRA, D. P. R. Sistemas, organização e métodos: uma abordagem gerencial, 13. ed. São Paulo: Atlas, 2002.

Serasa Experian, Indicador de Falência e Recuperações . Disponível em: <http://g1.globo.com/economia/noticia/2015/04/pedidos-de-falencias-sobem-573-em-marco-dizserasa-experian.html> . Acesso em: 10 ago. 2015. 